\title{
PARTICULARITIES OF FEMALE TRAINING IN MILITARY PHYSICAL EDUCATION
}

\author{
Robert STĂNCIULESCU \\ rstanciulescu@armyacademy.ro \\ “NICOLAE BĂLCESCU” LAND FOCES ACADEMY, SIBIU, ROMANIA
}

\begin{abstract}
The entire training process aims at completing the professional training of the military so that they can maintain a high level of work capacity and combat ability, even under multiple demands.

The morphological and functional characteristics of the military in this category require the organization and development of a well-planned, organized and managed training system that ensures that the assessment standards are met but at the same time does not produce physical, mental or functional disturbances of the body.
\end{abstract}

\section{KEYWORDS:}

Physical, psychic, combat, means, characteristics, process

\section{Introduction}

A level of development of the physical capacity specific to the deployment of the military actions that characterize the modern warfare is ensured by a complex process of training and requires the observation of the general scientific requirements of formation and development of the individual psycho-motor ability, depending on gender, physical and psychic qualities, way of life and personal attitude towards this category of training. The adaptation of the body to the extremely demanding functional efforts of the struggle presupposes a continuous activity of developing the basic physical qualities, together with the formation of skills and abilities specific to the various branches and military specialties, in closerelation to the the adaptation of the organism to the extremely demanding psychological demands.
In the process of transposing the model of an efficient fighter, it is necessary to carefully follow the coordinates to ensure it, physically normal development, health, resistance to weather conditions, perfect integration in the conditions of the area of action and resistance to long-lasting physical and mental stress. The complexity of the missions as well as the characteristics of the various branches and military specialties requires that in the preparation process they act to ensure these requirements. Thus, for the infantry and the scouts, the formation of fighters with very good physical and psychic resistance is desired, able to act quickly in unpredictable situations, to easily pass over the obstacles on the battlefield, to throw the grenades with precision and accuracy or to give proof of skillfulness in the close battle. Mountain troops must be tenacious fighters, resistant 
to moving in rough and rugged mountainous terrain, on foot or on skis, to climb quickly and skillfully and to have close combat skills. The military in the branch of artillery, engineering and tankers must have the strength, speed and skills necessary to easily mitigate the material contained in areas of reduced size, to be physically and mentally resilient to all types of effort and to know the procedures of swimming and crossing watercourses. Military chemists need exceptional physical and psychological resistance and must be able to act decisively in the conditions of oxygen deficiency and the existence of toxic gases, to deal with situations with high nervous load and to act easily with the equipment they have and military in the branch of signals must have a physical strength and exceptional response speed to easily handle the equipment in static or reduced mobility (Stănciulescu, 2017). Considering these aspects, specialists in the field need to identify the most efficient methods and means that, in agreement and the other characteristics of different types of effort, ensure the formation of a powerful physical capacity.

\section{Particularities of female training}

It is of paramount importance that the specialists of the field should know the essential aspects related to the morphofunctional characteristics of the female organism but also the types of effort to which the body is subjected because its adaptation due to external disturbances changes the values of its physiological indices.

\subsection{The influences of physical effort on the body}

The variety of types of physical effort exerted on the body induces two types of adaptation to restore it. The immediate adaptation in which the rebalancing of the physiological indices is done during the effort and even in the immediate aftermath of its cessation, and the late adaptation as it appears from the name, ensures functional improvement of the body at rest. Depending on oxygen supply, we can talk about anaerobic efforts and aerobic efforts (Alexandrescu, 1977). Anaerobic efforts are those in which the release of body energy is done in the absence of oxygen and which in turn can be two ways:

Alactacid anaerobic efforts characterized by the explosive development of a large amount of energy, increased muscle power, maximum energy flow, but low volume of work. In this type of effort, the duration of maintaining it at the maximum values is between 7 and 10 seconds then drops suddenly, because the muscular system is incapable of working at this intensity (Dragnea, A, 1996). Oxygen debt is paid at the end of the effort, so it takes time to recover the energy substrate.

Lactic acid anaerobic efforts, which last up to 60 seconds and are called like this due to lactic acid release. They are characterized by increased body strength (about half of the strength of the alactacid effort) over a period of 10-15 seconds up to 40 seconds after it begins to decrease. Body recovery is done after effort, one of the best methods being the active recovery.

Aerobic efforts are found in activities that last for 2-5 minutes and are also called endurance efforts, characterized by the body's ability to perform physical activity for a longer time at the same intensity. Body power is about $20-30 \%$ of the maximum of the alactacid anaerobic power but is offset by the large workload the body carries.

According to intensity we can distinguish the following types of effort:

- the maximum intensity effort that lasts for 10-15 seconds and which is characterized by a maximum energy flow;

- submaximal intensity effort of about one-minute duration and recovery of the body is done anaerobically;

- a high intensity effort lasting up to six minutes and the recovery of the energy substrate is done both aerobically and anaerobically; 
- low intensity effort, characterized by great volume, i.e. with a duration of one to several hours, in which the recovery of the body is done by aerobically.

Knowing these characteristics is of vital importance to both the specialists and the subjects with whom they work, as the complexity of the physical activities in the military-applied field is great and the specific action can demand the human body to the maximum.

\subsection{The particularities of female training}

In his works, Voltaire said that both man and woman should not be looked at in terms of what distinguishes them, but rather in terms of what connects them as the architects of the material and spiritual values of the world. The basis for the preparation of this category of staff is the same principles and rules used in male training, but it is necessary to know the morphological and functional particularities of the female organism which must be considered when making the efforts, the didactic principles and the methods acting on systems and functions of the body (Homenkov, 1997). At the same time, it is necessary to know that the most important differences between men and women are related to the height and weight that are lower in women, as well as the proportion of the muscular system to the weight, which represents $36 \%$ for women compared to $42 \%$ in men. This is the reason why, although missions are often the same for both categories of staff, these characteristics require standards of training and assessment adapted to the possibilities of the body. The heart of women is much smaller in size than the heart of men, therefore it is programmed to beat twice faster. Parameters of cardiovascular and respiratory systems activity are lower, so the oxygen consumption is lower than in men. Pulse is higher because women get tired faster than men when they make physical efforts, the recovery of the body is done in a more difficult way this also because women have fewer red blood cells than men, so a lower capacity of oxygenation of blood. The female muscular system is characterized by greater suppleness due to the higher elastin content, women being more flexible than men but being less powerful, therefore its development in all its forms of manifestation must be in the attention of the specialists. It is advisable to act especially for developing the strength of the basic muscle groups, especially the back muscles, the abdominal muscles as well as the upper and lower limbs, of which there is a great need in training for throwing grenades, running on the obstacle track, transporting specific materials or in selfdefense combat. The main methodical procedures used for the development of force are the following:

- the procedure of performing movements involving intense and rapid muscle contractions. This procedure does not refer to the increase in muscle mass but to the ability of the muscle to contract in the shortest possible time. It is especially used in disciplines where there is no need for muscle mass but for force in speed;

- isometric process in which the development of force is assured by pushing a static resistance, in which case the length of the muscle mass is not changed;

- the weight lifting method, which has as reference the progressive increase of the load;

- the POWER-TRAINING method Is a method used to speed up the force;

- the circuit process that aims to develop the main muscle groups.

Endurance is achieved especially by long runs where the intensity of the effort is small or medium, but about $20 \%$ less than in men. However, the results of multidisciplinary research on resistance intake show that the female body can achieve male resistance values, of course as a result of a proper training process. The following may be used as the main methodical procedures:

- the procedure of repeating the efforts with uniform intensities; 
- the procedure of repeating the effort with changing intensity;

- the process of variable effort, which is characterized by both volume and intensity variation.

The advantage of this type of training referes to, besides the fact that it can be used in any training conditions, the improvement of the cardiorespiratory function and it is considered a process with high efficiency also in the development of will and psychological resistance qualities of the military.

The development of the reaction and execution speed as well as the skillfulness also have an important role in providing a physical condition that can ensures the formation of battle skills in accordance with the missions, but also here it is necessary to consider the specificities mentioned above. A special mention should be made in the situation when women are in the post-natal period, when the body accumulates anabolic substances which favors the manifestation of the working capacity and allows to obtain results but in the first part of the re-training it is necessary to pay special attention to avoid jumps, lift weights, getting back to normality being done through long-term aerobic exercises as well as through general force development exercises.

To be effective, specialists in the field must take into account the following specific aspects:

- planning methods and means of action to develop physical skills requires rigorous planning and thorough knowledge of the characteristics of the body of people involved in the development process;

- carrying out careful and thorough coordination of the volume-intensity relationship in relation to the physical quality on which it is acted;

- particular attention will be paid to the observance of the principles from simple to complex and from easy to difficult;

- the results obtained during the preparation of the training will be well managed and the performance of the exercises with the highest efficiency for the development of a certain physical quality will be pursued;

- together with the development of basic physical skills, the development of will, courage, perseverance and self-confidence will be pursued;

- during training, special attention will be given to the recovery of the body by taking breaks in strict accordance with the established objectives.

In the entire training program it is necessary to take into account two elements that can endanger the training process, namely, on the one hand overloading the body through exaggerated efforts and, on the other hand, the excessive caution because of which the training is maintained at a lower level. My strong belief is that the specialists in the field, who need a thorough training, imagination, flexibility and adaptability to the specificities of the situations in the training programs, have a very important role in achieving the performances.

\section{Conclusions}

The experience of the recent conflicts made military experts consider unanimously the decisive role of the training system so that the army's personnel could at any moment intervene and decisively influence the course of events, constantly looking for the ways of physical training that in their content, in response to the dangers and risks to which the fighters are exposed, give realism to instruction and a faithful approach to the reality of the battlefield. The morphological and functional characteristics of the body of women are different from those of men and as a result provide a level of development of basic physical skills in order to accomplish certain physical and mental activities required by the accomplishment of the missions as well as adapting the body to the extreme functional efforts require a certain way of conducting the training process to ensure the desired efficiency. 


\section{REFERENCES}

Alexandrescu, C. (1997). Igiena educației fizice și sportului. Bucureşti: Editura SportTurism.

Dragnea, A. (1996). Antrenamentul sportiv. Bucureşti: Editura Didactică şi Pedagogică. Homenkov, L.S. (1997). Atletism. Bucureşti: Editura Sport-Turism.

Stănciulescu, R. (2017). Didactica activităţilor fizice cu caracter aplicativ militar. Sibiu: Editura Academiei Forţelor Terestre "Nicolae Bălcescu". 